\title{
Tratamento cirúrgico das lesões da aorta torácica utilizando parada circulatória total hipotérmica com perfusão cerebral retrógrada
}

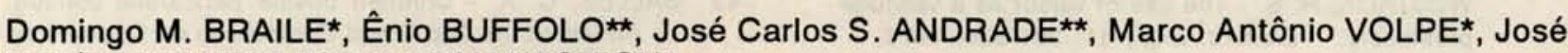
Honório PALMA**, Marcos ZAIANTCHICK*

RBCCV 44205-167

BRAILE, D. M.; BUfFOLO, E.; ANDRADE, J. C. S.; VOLPE, M. A.; PALMA, J. H.; ZAIANTCHICK, M. Tratamento cirúrgico das lesōes da aorta torácica utilizando parada circulatória total hipotérmica com perfusāo cerebral retrógrada. Rev. Bras. Cir. Cardiovasc., 7(2):96-106, 1992.

RESUMO: De setembro de 1991 a fevereiro de 1992, foram operados nove pacientes com lesōes da aorta torácica, usando parada circulatória total (PCT) hipotérmica profunda com perfusāo cerebral retrógrada (PCR), sendo seis do sexo masculino e três do feminino, com idade variando de 45 a 80 anos. Quatro deles tinham dissecçāo tipo $A$, três tinham aneurisma verdadeiro de aorta, um tinha uma associaçāo de aneurisma verdadeiro com dissecçāo tipo $\mathrm{A}$ e um tinha ectasia ânulo-aórtica associada a dissecção tipo B. A técnica utilizada foi a instalaçāo da circulação extracorpórea (CEC) tipo cava-cava-femoral com hipotermia profunda e parada circulatória total. Utilizou-se cardioplegia retrógrada sangūínea como método de preservação de miocárdio. Durante a PCT foi feita PCR usando a linha arterial conectada à cânula da VCS, com fluxo de 250 a $300 \mathrm{ml} / \mathrm{min}$, com PVC monitorizada no membro superior variando entre 30 e $40 \mathrm{cmH}_{2} \mathrm{O}$. A correção cirúrgica foi feita com tubo e patch de pericárdio bovino associados a cola biológica. O tempo de CEC variou de 75 até $169 \mathrm{~min}$, com PCT de 32 até $79 \mathrm{~min}$. e com PCR de 32 até $79 \mathrm{~min}$. Nāo houve óbito associado ao ato operatório e nem ao pós-operatório (PO) imediato. Houve apenas um óbito tardio por septicemia. Demais pacientes em seguimento ambulatorial. Os resultados obtidos representam um forte indicador de que a PCT com PCR protege o cérebro de forma mais eficiente que a PCT convencional, sendo vantajosa no tratamento cirúrgico das afeç̧ōes da aorta torácica que requerem PCT.

DESCRITORES: aneurismas de aorta, cirurgia; proteção cerebral.

\section{INTRODUÇĀO}

O tratamento cirúrgico dos aneurismas verdadeiros ou dissecçōes envolvendo a aorta torácica permanece como um dos mais complicados desafios tático-técnicos para a equipe cirúrgica ${ }^{7,18-20}$.

O dano isquêmico do sistema nervoso central figura, juntamente com os distúrbios da hemostasia, como uma das maiores complicaçōes que contribu- em para a grande morbi-mortalidade associada ao tratamento cirúrgico dessa patologia ${ }^{6,18-20}$.

O uso da parada circulatória total (PCT) em hipotermia profunda tem vantagens, como permitir um campo cirúrgico limpo e de fácil manipulação, sem excesso de cânulas e clamps; entretanto, traz consigo problemas como preservação do cérebro isquêmico, embolismo aéreo e distúrbios da crase sangüínea ${ }^{5,18-20}$.

Trabalho realizado no Instituto de Molésticas Cardiovasculares. Sảo José do Rio Preto, SP, e na Escola Paulista de Medicina, Sảo Paulo, SP, Brasil. Apresentado ao $19^{\circ}$ Congresso Nacional de Cirurgia Cardíaca. Sảo Paulo, SP, 7 a 9 de maio, 1992.

* Do Instituto de Molésticas Cardiovasculares.

* Da Escola Paulista de Medicina.

Endereço para separatas: Domingo M. Braile. Rua Castelo D' Água, 3030. 15015 São José do Rio Preto, SP, Brasil. 
BRAILE, D. M.; BUFFOLO, E.; ANDRADE, J. C. S.; VOLPE, M. A.; PALMA, J. H.; ZAIANTCHICK, M. - Tratamento cirúrgico das lesōes da aorta torácica utilizando parada circulatória total hipotérmica com perfusáo cerebral retrógrada. Rev. Bras. Cir. Cardiovasc., 7(2):96-106, 1992.

Recentemente foi introduzida a PCT hipotérmica com perfusão cerebral retrógrada (PCR) via veia cava superior ${ }^{8,10,18-21}$.

Os resultados clínicos obtidos por ambas as equipes, bem como os relatos de literatura são muito animadores.

Neste relato, apresentamos nossa recente experiência com o tratamento das lesōes da aorta torácica com uso da perfusão cerebral retrógrada.

\section{CASUÍSTICA E MÉTODOS}

De setembro de 1991 a fevereiro de 1992, foram operados nove pacientes (seis do sexo masculino e três do feminino), com idade variando de 45 a 80 anos ( $M=62,3 \pm 11,0$ anos) os quais apresentavam lesōes comprometendo a aorta torácica, com e sem acometimento da valva aórtica. O diagnóstico foi baseado na história clínica e nos exames complementares. Nenhum paciente era portador de lesão neurológica pregressa (Tabelas 1 e 2).

\section{Conduta Anestésica}

A) Pré-anestésico: depende das condições clínicas do paciente, podendo ser usada prometazina (Fenergan $\left.{ }^{8}\right) 50 \mathrm{mg} \mathrm{IM}$ (pacientes em mau estado geral) ou prometazina (Fenergan $($ ) $50 \mathrm{mg}$ IM associado a meperidina (Dolantina $₫$ ) $100 \mathrm{mg}$ IM (pacientes em regular ou bom estado geral), cerca de 45 minutos antes de vir para o centro cirúrgico.

B) Monitorizaçāo e cuidados: usa-se rotineiramente

* Colchāo térmico

* Cardioscópio

* Monitor com curva de PA

* Dois acessos venosos - importante excluir punçōes no pescoço. Deve ser dissecada uma veia calibrosa no membro superior. Isso vai permitir a medida da PVC quando for realizada a PCR.

* Oxímetro de pulso

* Termômetros de nasofaringe, tímpano, reto e miocárdio.

C) Induçăo anestésica: são usadas as seguintes drogas

TABELA 1

DADOS CLÍNICOS

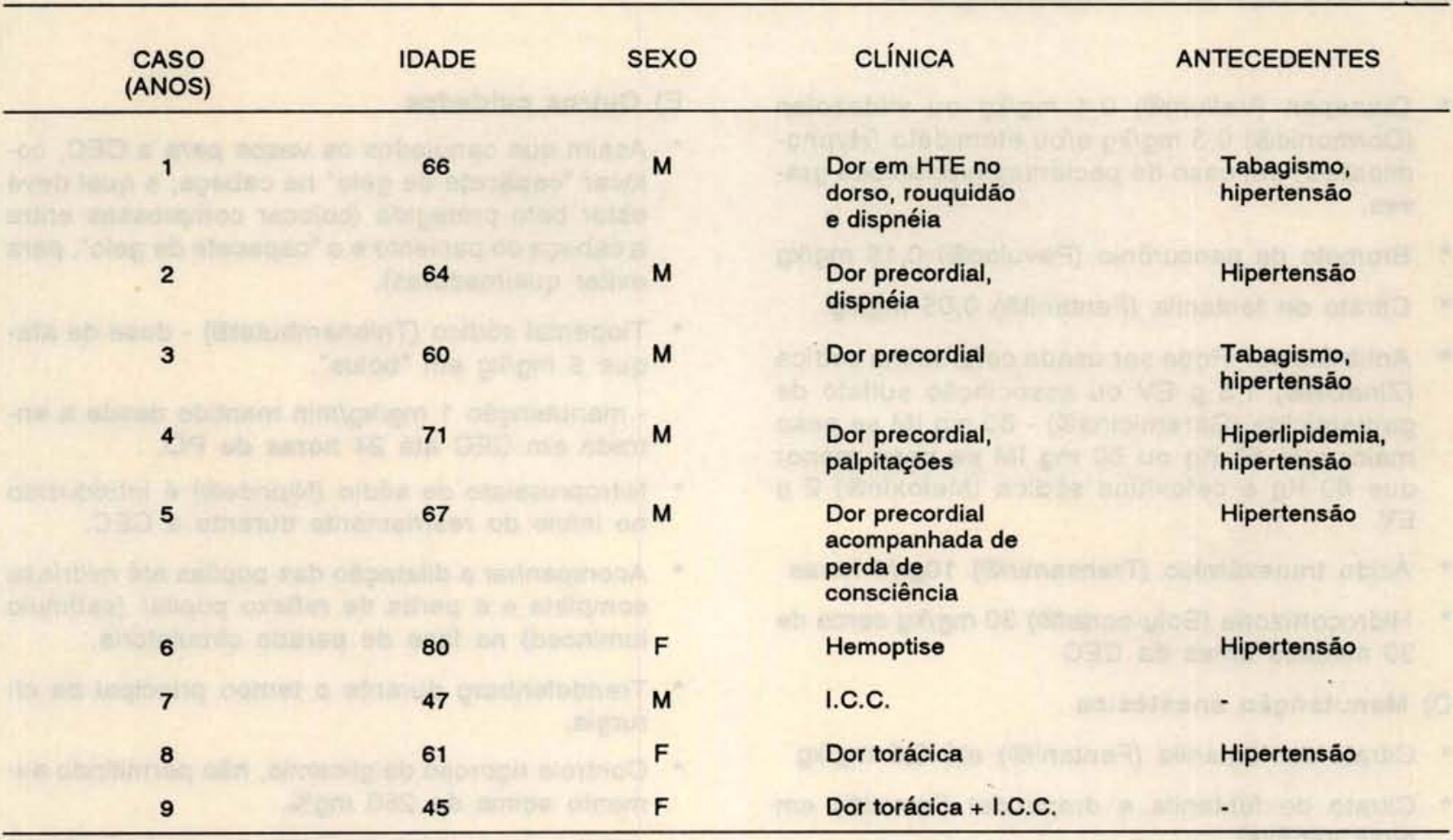

HTE= Hemitórax esquerdo; $M=$ masculino; $F=$ feminino;

I. C. $\mathrm{C} .=$ Insuficiência cardíaca congestiva. 
BRAILE, D. M.; BUFFOLO, E.; ANDRADE, J. C. S.; VOLPE, M. A.; PALMA, J. H.;ZAIANTCHICK, M. - Tratamento cirúrgico das lesōes da aorta torácica utilizando parada circulatória total hipotérmica com perfusão cerebral retrógrada. Rev. Bras. Cir. Cardiovasc., 7(2):96-106, 1992.

TABELA 2

INVESTIGAÇÃO E DIAGNÓSTICO

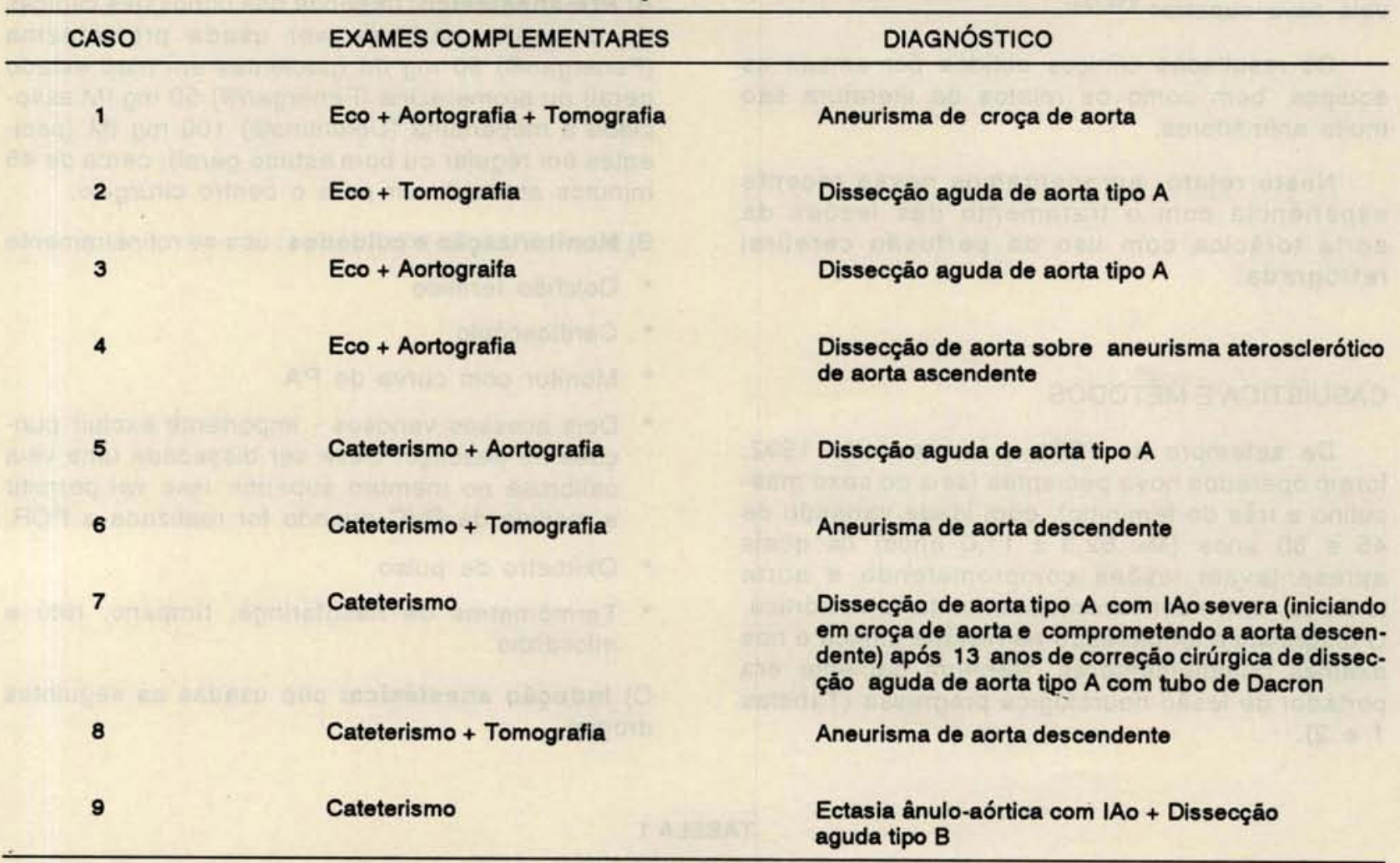

Eco = Ecocardiograma; $\mid A O=$ Insuficiência aórtica

* Diazepan (Valium®) $0,4 \mathrm{mg} / \mathrm{kg}$ ou midazolan (Dormonid@) 0,3 mg/kg e/ou etomidato (Hypnomidate $\left.{ }^{\circledR}\right)$ em caso de pacientes hipotensos graves.

* Brometo de pancurônio (Pavulon®) $0,15 \mathrm{mg} / \mathrm{kg}$

* Citrato de fentanila (Fentanil囚) $0,05 \mathrm{mg} / \mathrm{kg}$

* Antibióticos - Pode ser usada cefuroxima sódica (Zinacef(B) 1,5 g EV ou associaçāo sulfato de gentamicina (Garamicina ${ }^{\circledR}$ ) - $80 \mathrm{mg}$ IM se peso maior que $60 \mathrm{Kg}$ ou $60 \mathrm{mg}$ IM se peso menor que $60 \mathrm{Kg}$ e cefoxitina sódica (Mefoxin囚) $2 \mathrm{~g}$ EV.

* Ácido tranexâmico (Transamin®) $10 \mathrm{gr} / 4$ horas

* Hidrocortizona (Solu-cortef囚) $30 \mathrm{mg} / \mathrm{kg}$ cerca de 30 minutos antes da CEC.

\section{D) Manutenção anestésica}

* Citrato de fentanila (Fentanil囚) até $0,5 \mathrm{mg} / \mathrm{kg}$

* Citrato de fentanila e droperidol (Inoval®) em dose variável.

* Isoflurano (Forane $\left.{ }^{8}\right)$ até $1 \%$

\section{E) Outros cuidados}

* Assim que canulados os vasos para a CEC, colocar "capacete de gelo" na cabeça; a qual deve estar bem protegida (colocar compressas entre a cabeça do paciente e o "capacete de gelo", para evitar queimaduras).

* Tiopental sódico (Thionembutal囚) - dose de ataque $5 \mathrm{mg} / \mathrm{kg}$ em "bolus".

- manutenção $1 \mathrm{mg} / \mathrm{kg} / \mathrm{min}$ mantido desde a entrada em CEC até 24 horas de PO.

* Nitroprussiato de sódio (Nipride®) é introduzido no início do resfriamento durante a CEC.

* Acompanhar a dilatação das pupilas até midríase completa e a perda de reflexo pupilar (estímulo luminoso) na fase de parada circulatória.

* Trendelenburg durante o tempo principal da cirurgia.

* Controle rigoroso de glicemia, não permitindo aumento acima de $250 \mathrm{mg} \%$.

* Administração de bicarbonato de sódio $8,4 \%$ no retorno da circulação com controle gasométrico. 
BRAILE, D. M.; BUFFOLO, E.; ANDRADE, J. C. S.; VOLPE, M. A.; PALMA, J. H.; ZAIANTCHICK, M. - Tratamento cirúrgico das lesōes da aorta torácica utilizando parada circulatória total hipotérmica com perfusão cerebral retrógrada. Rev. Bras. Cir. Cardiovasc., 7(2):96-106, 1992.

* Compressāo das carótidas no momento de reinício da CEC.

* Retirada da posição de Trendelenburg após o reinício da CEC.

* Introdução do nitroprussiato de sódio (Nipride®) novamente no reaquecimento.

* Acompanhar o fechamento das pupilas e o retorno do reflexo pupilar (estímulos luminosos).

* Ligar o colchão térmico para auxiliar no reaquecimento.

\section{Técnica de Perfusão e Resfriamento}

Após heparinização sistêmica com $4 \mathrm{mg} / \mathrm{kg}$, é estabelecida CEC tipo cava-cava-femoral com fluxo de $2,41 / \mathrm{m}^{2} \mathrm{~min}$. com $70 \%$ de $\mathrm{O}_{2}$ na relação 1:1. É usado oxigenador de membrana com shunt para recirculação do sangue. Promove-se o abaixamento da temperatura até $18^{\circ} \mathrm{C}$, tendo como guias as temperaturas nasofaríngea, timpânica e retal. Conforme progride o resfriamento, diminui-se o fornecimento de $\mathrm{O}_{2}$ vagarosamente até chegar em $40 \%$ de $\mathrm{O}_{2}$ na relação 1/2:1.

Nos portadores de insuficiência aórtica, deve ser feita massagem cardíaca para evitar a distensão do ventrículo esquerdo, enquanto prosseguem a perfusão e o resfriamento.

O circuito para perfusão cerebral retrógrada é feito conectando-se a linha arterial à cânula da veia cava superior por meio de conectores em $Y$, conforme Figura 1.

A PCT é feita com pinçamento da linha venosa inicialmente, seguindo-se de pinçamento da linha arterial, para promover a parada com paciente "cheio". Uma vez em PCT, é aberto o shunt da recirculação, enquanto não se inicia a PCR. O fluxo pelo shunt é de 1 a $1,5 \mathrm{l} / \mathrm{min}$.

A PCR em PCT hipotérmica é feita usando-se o rolete e a linha arteriais conectados à cânula da veia cava superior. São realizados, pelo cirurgião, os pinçamentos da conexão veia cava superiorveia cava inferior e da linha arterial femoral, enquanto o perfusionista faz o pinçamento do shunt da recirculação e o despinçamento da linha arterial, dando início à perfusâo cerebral retrógrada (Figura 2). O fluxo varia de 250 a $300 \mathrm{ml} / \mathrm{min}$, tendo como guias o rolete arterial e a PVC, que deve atingir no máximo $40 \mathrm{cmH}_{2} \mathrm{O}$.

O sangue do campo cirúrgico retorna pela luz dos vasos da cabeça, sendo aspirado para o oxigenador pelos aspiradores de campo.

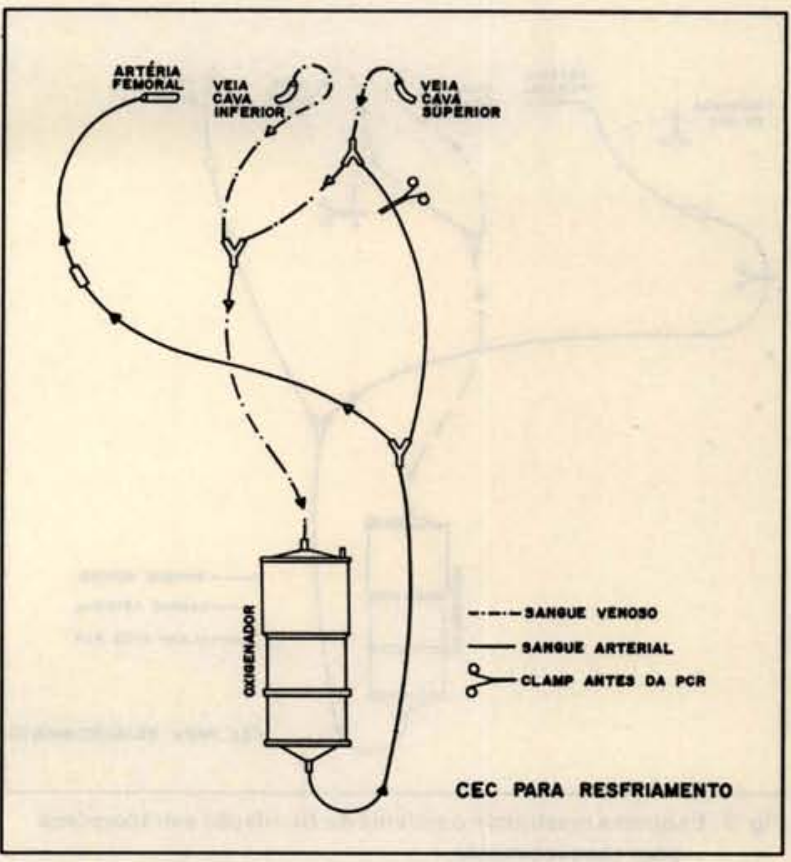

Fig. 1 - Esquema mostrando o sistema de circulação extracorpórea para resfriamento.

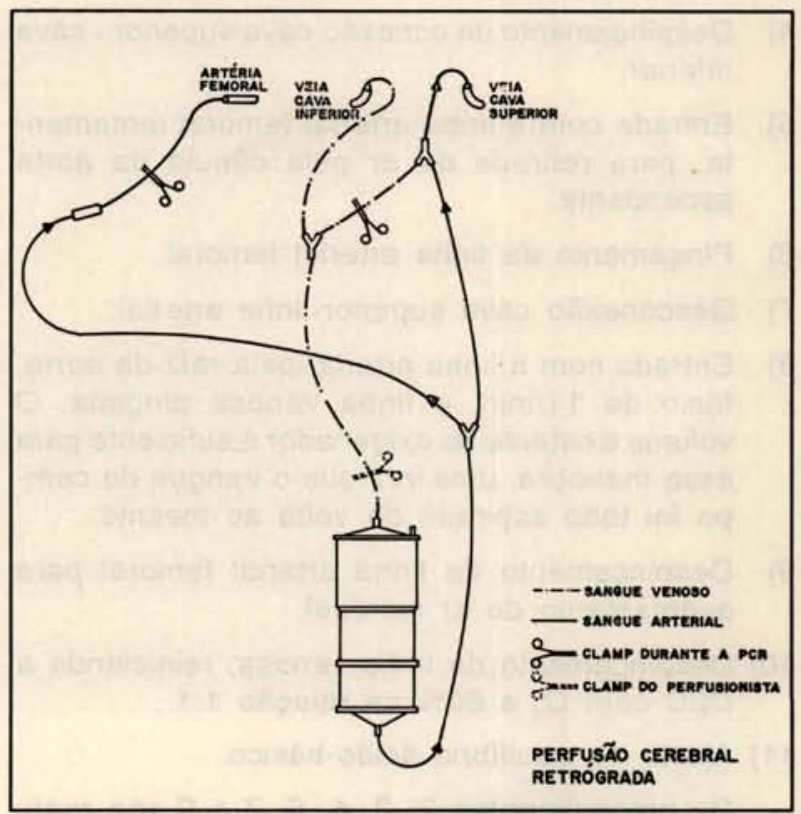

Fig. 2 - Esquema mostrando o sistema de perfusão cerebral retrógrada.

Para restabelecimento da CEC são necessários (Figura 3):

1) Parada da PCR.

2) Pinçamento da conexāo cava superior-linha arterial. 

da aorta torácica utilizando parada circulatória total hipotérmica com perfusão cerebral retrógrada. Rev. Bras. Cir. Cardiovasc., 7(2):96-106, 1992.

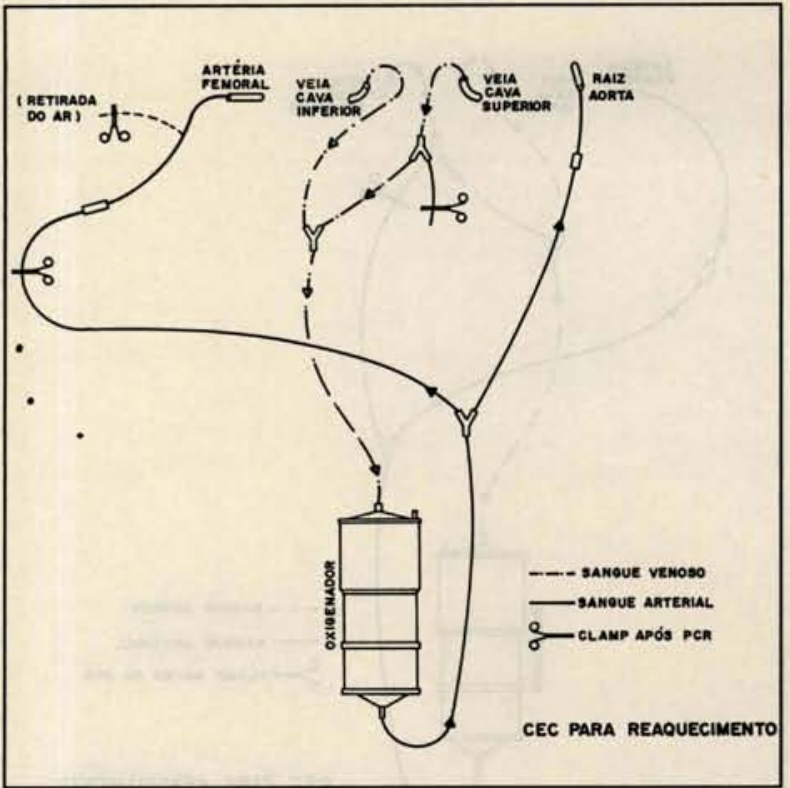

Fig. 3-Esquema mostrando o sistema de circulação extracorpórea para reaquecimento.

3) Despinçamento da linha arterial femoral.

4) Despinçamento da conexão cava superior - cava inferior.

5) Entrada com a linha arterial femoral lentamente, para retirada do ar pela cânula da aorta ascendente.

6) Pinçamento da linha arterial femoral.

7) Desconexão cava superior-linha arterial.

8) Entrada com a linha arterial pela raíz da aorta, fluxo de $11 / \mathrm{min}$, e linha venosa pinçada. 0 volume existente no oxigenador é suficiente para essa manobra, uma vez que o sangue do campo foi todo aspirado de volta ao mesmo.

9) Despinçamento da linha arterial femoral para esgotamento do ar residual.

10) Despinçamento da linha venosa, reiniciando a CEC com $\mathrm{O}_{2}$ a $60 \%$ na relaçāo 1:1.

11) Ajuste do equilíbrio ácido-básico.

Os procedimentos $2,3,4,6,7$ e 9 são realizados pelo cirurgiāo e os demais pelo perfusionista.

Faz-se o reaquecimento tendo como guia a temperatura nasofaríngea. Procurar manter sempre um diferencial entre $\mathrm{a}_{2} \mathrm{O}$ do trocador de calor e a temperatura nasofaríngea de no máximo $10^{\circ} \mathrm{C}$. A temperatura deve atingir $37^{\circ} \mathrm{C}$ no termômetro nasofaríngeo. O colchāo térmico é usado como auxiliar após o paciente ter atingido $34^{\circ} \mathrm{C}$, mais uma vez tendo como referência a temperatura naso- faríngea (medida de segurança para diminuir a possibilidade de queimaduras).

A cardioplegia é retrógrada para indução e manutençāo, sendo administrada juntamente com o sangue durante o resfriamento. Na reperfusāo, inicia-se o aquecimento da cardioplegia antes do aquecimento do corpo.

A temperatura do miocárdio é medida por um termômetro de agulha no septo.

\section{Técnica Operatória}

A artéria femoral é canulada após heparinização sistêmica. O tórax e o pericárdio são abertos cuidadosamente. $O$ bypass cardiopulmonar é tipo cavacava-femoral. O paciente é resfriado até cerca de $18^{\circ} \mathrm{C}$ (temperatura nasofaríngea) e, enquanto isso, a veia ázigos e as cavas, que foram previamente laçadas, são garroteadas. $O A D$ é aberto, sendo confeccionada uma sutura em bolsa no seio coronariano, sob visão direta. Instala-se o sistema cardioplegia retrógrada com sonda Foley $\mathrm{N}^{2} 18$ ou 20. Após a obtençāo do resfriamento corpóreo e sob cardioplegia, o coração pára e, posteriormente, inicia-se a PCR.

Efetuada a PCT hipotérmica, é iniciada, imediatamente, a PCR, monitorizando-se continuamente a PVC no membro superior. Deixar a PVC no máximo em $40 \mathrm{cmH}_{2} \mathrm{O}$. Todas as perfusōes cerebrais devem ser contínuas, com fluxo de 250 a $300 \mathrm{ml} / \mathrm{min}$. A aorta é aberta, sendo visibilizado o sítio de dissecção e/ou o interior do aneurisma verdadeiro com retirada dos trombos murais. É sempre importante analisar o grau de comprometimento dos vasos da cabeça e também certificar-se do retorno de sangue retrogradamente pela luz dos mesmos. Realiza-se a endo-aneurismorrafia usando-se tubos e/ou patchs de material protético para a reconstrução da aorta ascendente e do arco aórtico. Nos casos descritos, - material das próteses foi, exclusivamente, pericárdio bovino. Procura-se a preservação da valva aórtica sempre que possível. Em caso de troca valvar aórtica, opta-se pela técnica de Bental e De Bonno (usando um tubo valvulado), ou realiza-se a troca da valva e a reconstruçāo da aorta ascendente independentemente. Quando há comprometimento de óstio coronariano, realiza-se a revascularização do miocárdio com pontes de safena para as artérias comprometidas. Havendo envolvimento da aorta torácica descendente, associa-se a técnica "tromba de elefante" com tubo de pericárdio bovino. É de grande importância o auxílio da cola biológica, principalmente nos casos de dissecção. A Tabela 3 registra a conduta cirúrgica de acordo com o diagnóstico. Após o término do tempo principal da cirurgia, procede-se ao reinício da CEC. Introduz-se 
BRAILE, D. M.; BUFFOLO, E.; ANDRADE, J. C. S.; VOLPE, M. A.; PALMA, J. H.; ZAIANTCHICK, M. - Tratamento cirúrgico das lesōes da aorta torácica utilizando parada circulatória total hipotérmica com perfusão cerebral retrógrada. Rev. Bras. Cir. Cardiovasc., 7(2):96-106, 1992.

TABELA 3

DIAGNÓSTICO E CONDUTA CIRÚRGICA

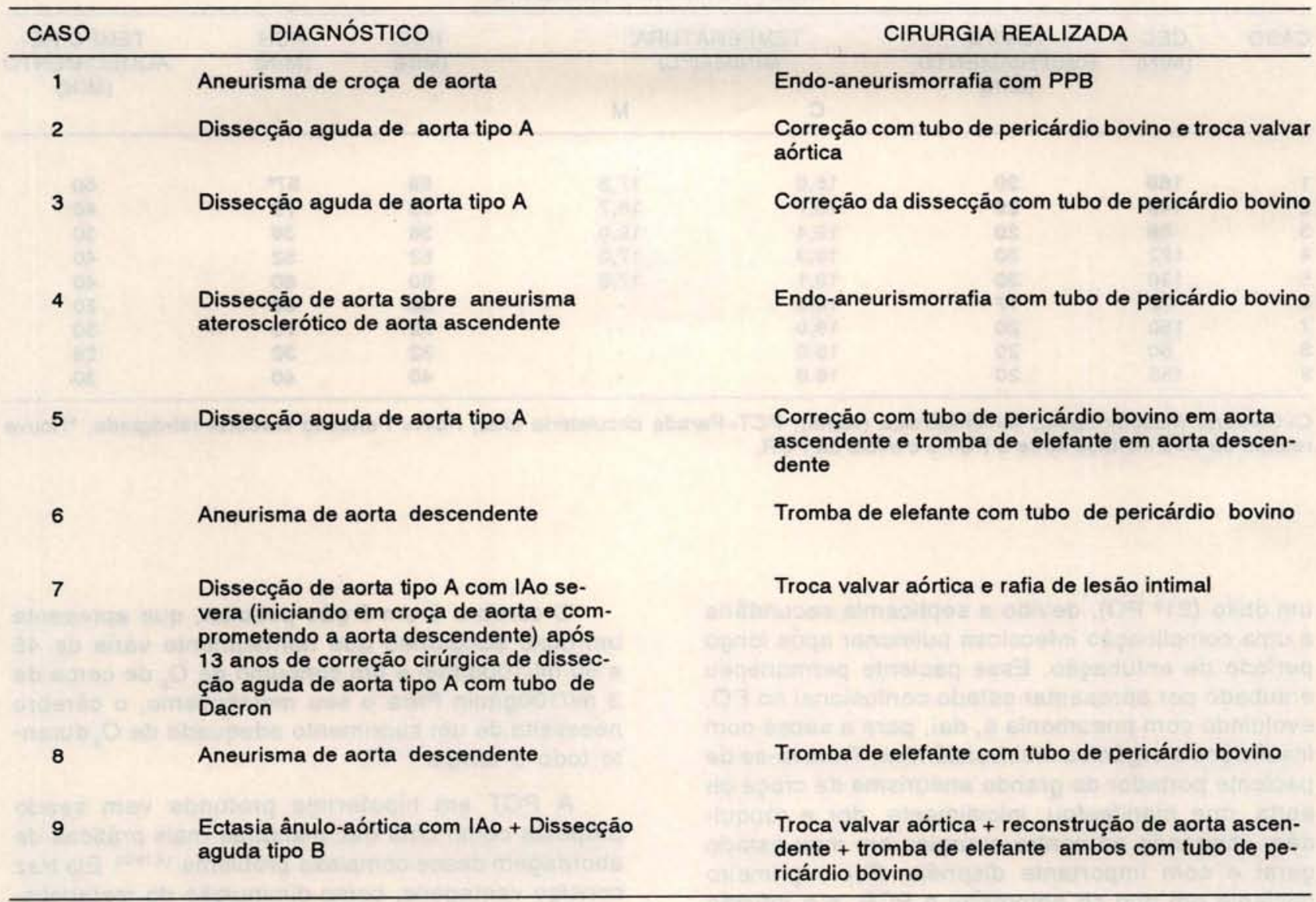

$\mid A O=$ Insuficiência aórtica; $P P B=$ patch de pericárdio bovino.

uma cânula arterial na aorta, ou prótese que substitui a aorta ascendente, e reinicia-se a CEC ainda pela femoral, retirando-se todo o ar pela cânula da aorta. $\mathrm{O}$ anestesista comprime as carótidas comuns, a posição de Trendelenburg é mantida e os pulmōes săo hiperinsuflados. Tão logo todo o ar tenha sido eliminado, inverte-se a circulaçāo, passando a linha arterial para a cânula da aorta ascendente, mudando o fluxo arterial para anterógrado pela aorta. Assim que a CEC é restabelecida pela cânula aórtica, é usada a cânula femoral para retirada do ar remanescente. Terminada essa manobra, procedese à retirada da cânula femoral e à rafia desse vaso. Enquanto é realizado o reaquecimento, elimina-se todo o ar das cavidades cardíacas, puncionando a ponta do ventrículo esquerdo, antes que o coraçāo volte a bater. É sempre conveniente deixar um vent na aorta ascendente, que servirá para retirada de ar residual e para medir a pressāo da raíz da aorta. A saída de CEC é feita de maneira habitual, após o reaquecimento.

\section{RESULTADOS}

Foram operados nove pacientes com afecçōes da aorta torácica utilizando a parada circulatória total hipotérmica profunda com perfusão cerebral retrógrada via veia cava superior.

O tempo de CEC variou de 75 a $169 \mathrm{~min}(M=124$ $\pm 35,55 \mathrm{~min}$ ) com resfriamento que variou de 17 a $30 \mathrm{~min}(\mathrm{M}=21,9 \pm 4,70 \mathrm{~min})$ e temperatura mínima nasofaríngea que variou de 18,0 a $19,4^{\circ} \mathrm{C}(\mathrm{M}=18,4$ $\left.\pm 0,55^{\circ} \mathrm{C}\right)$. A parada circulatória total hipotérmica profunda esteve entre 32 e $79 \min (M=51,8 \pm 16,44$ min) com perfusāo cerebral retrógrada de 32 a 79 $\min (M=51,6 \pm 16,30 \mathrm{~min})$, devido a um retardo de dois minutos para entrada em PCR em um dos pacientes. Em todos os casos foi feita perfusāo cerebral retrógrada contínua. O reaquecimento foi feito em tempo que variou de 20 a $60 \mathrm{~min}(M=35,3$ $\pm 11,45 \mathrm{~min})$, conforme Tabela 4 .

Não houve óbito associado ao ato operatório e nem ao PO imediato. No PO tardio houve apenas 
BRAILE, D. M.; BUFFOLO, E.; ANDRADE, J. C. S.; VOLPE, M. A.; PALMA, J. H.; ZAIANTCHICK, M. - Tratamento cirúrgico das lesöes da aorta torácica utilizando parada circulatória total hipotérmica com perfusão cerebral retrógrada. Rev. Bras. Cir. Cardiovasc., 7(2):96-106, 1992.

\begin{tabular}{|c|c|c|c|c|c|c|c|}
\hline \multirow{3}{*}{ CASO } & \multirow{3}{*}{$\begin{array}{l}\text { CEC } \\
\text { (MIN) }\end{array}$} & \multirow{3}{*}{$\begin{array}{l}\text { TEMPO } \\
\text { RESFRIAMENTO } \\
\text { (MIN) }\end{array}$} & \multicolumn{3}{|c|}{$\begin{array}{c}\text { TABELA } 4 \\
\text { PERFUSĀO E RESFRIAMENTO }\end{array}$} & \multirow{3}{*}{$\begin{array}{l}\text { PCR } \\
\text { (MIN) }\end{array}$} & \multirow{3}{*}{$\begin{array}{l}\text { TEMPO RE- } \\
\text { AQUECIMENTO } \\
\text { (MIN) }\end{array}$} \\
\hline & & & \multicolumn{2}{|c|}{$\begin{array}{l}\text { TEMPERATURA } \\
\text { MÍNIMA }\left({ }^{\circ} \mathrm{C}\right)\end{array}$} & \multirow[t]{2}{*}{$\begin{array}{l}\text { PCT } \\
\text { (MIN) }\end{array}$} & & \\
\hline & & & C & $M$ & & & \\
\hline 1 & 169 & 20 & 18,0 & 17,8 & 59 & $57^{\star}$ & 60 \\
\hline 2 & 149 & 20 & 18,7 & 18,7 & 79 & 79 & 40 \\
\hline 3 & 86 & 20 & 19,4 & 19,0 & 36 & 36 & 30 \\
\hline 4 & 122 & 30 & 18,3 & 17,0 & 52 & 52 & 40 \\
\hline 5 & 130 & 30 & 19,1 & 17,8 & 60 & 60 & 40 \\
\hline 6 & 75 & 17 & 18,0 & - & 38 & 38 & 20 \\
\hline 7 & 150 & 20 & 18,0 & - & 70 & 70 & 30 \\
\hline 8 & 80 & 20 & 18,0 & - & 32 & 32 & 28 \\
\hline 9 & 155 & 20 & 18,0 & - & 40 & 40 & 30 \\
\hline
\end{tabular}

$\mathrm{C}=$ Corporal (nasofaríngea); $\mathrm{M}=$ Miocárdica (septo); $\mathrm{PCT}=\mathrm{Parada}$ circulatória total; $\mathrm{PCR}=\mathrm{Perfusāo} \mathrm{cerebral} \mathrm{retrógrada.}{ }^{\star} \mathrm{Houve}$ retardo de dois minutos entre a PCT e o início da PCR.

um óbito $\left(21^{\circ} \mathrm{PO}\right)$, devido a septicemia secundária a uma complicação infecciosa pulmonar após longo período de entubaçāo. Esse paciente permaneceu entubado por apresentar estado confusional no $\mathrm{PO}$, evoluindo com pneumonia e, daí, para a sépse com insuficiência orgânica multissistêmica. Tratava-se de paciente portador de grande aneurisma de croça de aorta, que manifestou, inicialmente, dor e rouquidāo, chegando ao centro cirúrgico em mau estado geral e com importante dispnéia. Foi o primeiro paciente em que se empregou a $\mathrm{PCR}$, e a infusāo na veia cava superior foi feita com a recirculaçāo do oxigenador aberta, baseando-se apenas na PVC, com fluxo estimado em 250 a $300 \mathrm{ml} / \mathrm{min}$. Os demais pacientes foram submetidos à PCR com recirculação fechada e controle exato do volume infundido na veia cava superior (250 a $300 \mathrm{ml} / \mathrm{mim})$. Estes evoluíram bem, com tempo de permanência médio de dois dias na UTI de PO. Nāo houve complicaçōes tardias, estando todos os pacientes em seguimento ambulatorial.

Os exames pós-operatórios, tais como eco, cateterismo, tomografia ou aortografia têm demonstrado resultados cirúrgicos satisfatórios.

\section{COMENTÁRIOS}

Desde há muito, os aneurismas e as dissecçōes de aorta torácica vêm desafiando as capacidades tática e técnica dos cirurgiōes, que ficam divididos entre a necessidade da correçāo cirúrgica da lesão e a possibilidade do dano cerebral conseqüente às mudanças circulatórias necessárias para tanto $7,18-20$.
O cérebro é um órgão peculiar, que apresenta um fluxo sangüíneo que normalmente varia de 45 a $50 \mathrm{ml} / 100 \mathrm{~g} / \mathrm{min}$ e um consumo de $\mathrm{O}_{2}$ de cerca de $3 \mathrm{ml} / 100 \mathrm{~g} / \mathrm{min}$ Para o seu metabolismo, o cérebro necessita de um suprimento adequado de $\mathrm{O}_{2}$ durante todo o tempo 1, 3,6.

A PCT em hipotermia profunda vem sendo proposta como uma das maneiras mais práticas de abordagem desse complexo problema ${ }^{14,18-20}$. Ela traz consigo vantagens, como diminuiçāo do metabolismo cerebral e, portanto, diminuição da necessidade de oxigênio ${ }^{4,18-20}$. Propicia um campo cirúrgico limpo e de fácil manipulaçāo, tornando dispensável o uso de clamps e cânulas para perfusāo cerebral seletiva. Todas essas vantagens tornam mais simples a cirurgia em parada circulatória total ${ }^{5,18-20}$. Isso justifica o uso dessa técnica pelas equipes, com resfriamento até $18^{\circ} \mathrm{C}$ em tempo médio de 21,9 minutos. Entretanto, apresenta, também, algumas desvantagens, como "proteger" o cérebro por no máximo 60 minutos; apresentar risco de embolismo aéreo ou de partículas e provocar distúrbios importantes à crase sangüínea, particularmente à coagulaçāo 4, 7, 11, 15, 16, 18-21.

A parada circulatória total em hipotermia profunda nāo é totalmente segura, uma vez que ainda hoje nāo se conhece o grau exato de proteçāo cerebral que confere; bem como qual seria o nível ideal de hipotermia para a melhor preservaçăo cerebral na parada circulatória total $2,4,12,13,20,21$.

Sabendo disso, ambas as equipes procuraram associar um método para aumentar a proteçāo cerebral durante esse período crítico, optando, assim, pela perfusão cerebral retrógrada. 
BRAILE, D. M.; BUFFOLO, E.; ANDRADE, J. C.S.; VOLPE, M. A.; PALMA, J. H.; ZAIANTCHICK, M. - Tratamento cirúrgico das lesōes da aorta torácica utilizando parada circulatória total hipotérmica com perfusāo cerebral retrógrada. Rev. Bras. Cir. Cardiovasc., 7(2):96-106, 1992.

A retroperfusão cerebral surgiu inicialmente para combater o embolismo aéreo maciço acidental durante 0 bypass cardiopulmonar ${ }^{10}$. Posteriormente foi proposta como método para expelir 0 ar interior dos vasos da cabeça nos casos de parada circulatória total para correção de afecçōes da aorta torácica ${ }^{18-20}$. LEMOLE et alii ${ }^{8}$ foram os primeiros a relatar a PCR intermitente, via veia cava superior, como uma maneira de fornecer oxigênio para o cérebro nesse período crucial. Propunham a utilização de um sistema seletivo para bombeamento do sangue, ficando dois minutos parado para cada dez minutos de bombeamento. No final da década de 80, UEDA et alii ${ }^{18-20}$ estenderam e simplificaram essa técnica, propondo a PCR contínua usando um circuito que utiliza a linha e 0 rolete arteriais para bombeamento na veia cava superior.

Também adotamos técnica semelhante empregando retroperfusāo cerebral contínua com tempo médio de $51,6 \mathrm{~min}$ e fluxo de 250 a $300 \mathrm{ml} / \mathrm{min}$. Nesse contexto, a PCR surge como método que, associado à PCT hipotérmica profunda, tenta fornecer maior proteção ao cérebro isquêmico ${ }^{18-20,21}$. É muito provável que a PCR mantenha o metabolismo cerebral num estado de equilíbrio dinâmico (steadystate), provendo suporte metabólico suficiente para manter uma atividade cerebral em baixos níveis, conforme comprovado por UEDA et alii ${ }^{1820}$. Ela ainda apresenta outras vantagens, como: a) manter um fluxo de sangue reverso nas artérias que vão ao cérebro, dificultando, assim, o embolismo aéreo e de partículas; b) reduzir a formação de micro-agregados de hemáceas, garantindo, assim, menor possibilidade de injúria cerebral ao nível capilar; c) manter a temperatura cerebral, evitando o aquecimento do cérebro pelo bombeamento constante de sangue a baixa temperatura ${ }^{18-20,21}$.

USUl et alii ${ }^{21}$ demonstraram, em cāes, que, durante PCR, apenas $20 \%$ do volume infundido retorna para aorta, sendo que o restante drena para o território da veia cava inferior. Acreditam que tal fato se deva a anastomoses veno-venosas ou venocapilares-venosas existentes no cérebro desses animais. Todavia, existem problemas relacionados à PCR no homem. A presença de válvulas no sistema venoso que drena na veia cava superior poderia oferecer resistência ao fluxo reverso durante a retroperfusão cerebral. As válvulas de maior importância estão nas veias jugulares internas a menos de $35 \mathrm{~mm}$ de suas desembocaduras nas veias braquiocefálicas correspondentes '. Nāo se sabe até que ponto essas válvulas podem prejudicar o fluxo reverso pelo sistema venoso. A Escola Paulista de Medicina vem desenvolvendo um trabalho, com dissecçōes em cadáveres, mostrando serem essas válvulas rudimentares e praticamente incontinentes*, - que também é defendido por UEDA \& MIKI ${ }^{17}$.

Para maior segurança, deve ser medida a PVC concomitantemente à análise do retorno de sangue retrogradamente pela luz dos vasos da cabeça. A presença de uma PVC anormalmente alta acompanhada de um baixo retorno sangüíneo por via retrógrada deve alertar o cirurgiāo sobre a possibilidade de obstáculos à perfusāo cerebral pela veia cava superior. Contudo, a presença de uma PVC normal não garante a eficiência da retroperfusão cerebral, uma vez que podem existir fístulas artério-venosas, oferecendo caminhos preferenciais ao sangue e impedindo sua chegada ao parênquima cerebral. A medida da saturação de $\mathrm{O}_{2}$ do sangue que retorna pelo sistema arterial pode auxiliar nesse diagnóstico. Disso conclui-se que, para maior segurança, deve ser feita uma análise conjunta da PVC e do retorno sangüíneo retrógrado que chega até a luz da aorta. O presente estudo apresentou um número limitado de pacientes, mas é nossa impressão que a parada circulatória total em hipotermia profunda com perfusāo cerebral retrógrada é mais eficiente na preservação do cérebro que a parada circulatória total hipotérmica profunda convencional ${ }^{18-20,21}$.

Os resultados nos levam a concluir que o método utilizado é simples, facilmente reprodutível e vantajoso no tratamento cirúrgico das afecçōes da aorta torácica, que exigem parada circulatória total em hipotermia profunda para o seu tratamento.

Acreditamos que, com futuras pesquisas e trabalhos experimentais, a perfusão cerebral retrógrada possa assumir um papel ainda mais importante, proporcionando uma proteção cerebral mais eficiente e garantindo tempos maiores de parada circulatória total; além de permitir menores graus de hipotermia, afetando menos a homeostase sangüínea.

\footnotetext{
* José Honório Palma, Comunicação Pessoal, Escola Paulista de Medicina, 1992.
} 
BRAILE, D. M.; BUFFOLO, E.; ANDRADE, J. C. S.; VOLPE, M. A.; PALMA, J. H.; ZAIANTCHICK, M. - Tratamento cirúrgico das lesōes da aorta torácica utilizando parada circulatória total hipotérmica com perfusão cerebral retrógrada. Rev. Bras. Cir. Cardiovasc., 7(2):96-106, 1992.

\section{RBCCV 44205-167}

BRAILE, D. M.; BUFFOLO, E.; ANDRADE, J. C. S.; VOLPE, M. A.; PALMA, J. H.; ZAIANTCHICK, M. - Surgical treatment of the pathologies involving thoracic aorta using deep hypothermic total circulatory arrest with retrograde cerebral perfusion. Rev. Bras. Cir. Cardiovasc., 7(2):96-106,1992.

ABSTRACT: From September 1991 to February 1992, nine patients presenting thoracic aorta pathologies were submitted to surgery using deep hypothermic total circulatory arrest with retrograde cerebral perfusion. Six patients were male and three female, with ages ranging from 45 to 80 years. Four had type $A$ dissection, three had true aorta aneurysm, one had true aneurysm associated with type $A$ dissection and one had anulusaorta ectasia associated with type B dissection. A cava-cava-femoral cardiopulmonary bypass was established with deep hypothermia and total circulatory arrest. Retrograde blood cardioplegia was used for myocardial preservation. During total circulatory arrest retrograde cerebral perfusion was made using arterial line cannulated to the superior vena cava with a flow of 250 to $300 \mathrm{ml} / \mathrm{min}$ the central venous pressure monitored at the arm ranged between 30 and $40 \mathrm{cmH} 20$. Surgical repair was achieved using bovine pericardial tube and patch associated to the biological glue. Duration of cardiopulmonary bypass ranged from 75 to 169 $\mathrm{min}$, total circulatory arrest from 32 to $79 \mathrm{~min}$ and retrograde cerebral perfusion from 32 to $79 \mathrm{~min}$. There was no mortality associated to surgery or to immediate postoperative period. There was only one late death, due to septcemia. All other patients are on follow-up. The results show that total circulatory arrest with retrograde cerebral perfusion protects the brain more effectively than conventional total circulatory arrest during surgical treatment of thoracic aorta pathologies that require total circulatory arrest.

DESCRIPTORS: aneurysms, aortic, surgery; cerebral protection.

\section{REFERÊNCIAS BIBLIOGRÁFICAS}

1 AULER Jr., J. O. C. - Proteção cerebral: cirurgia cardiaca. In: Congresso Brasileiro de Anestesiologia, 38, Porto Alegre, 1991. Resumo das contribuiçōes científicas. Porto Alegre, Socidade de Anestesiologia do Rio Grande do Sul, 1991. p. 18.

2 CLARKSON, P. M.; MaCARTHUR, B. A.; BARRATBOYES, B. G.; WHITLOCK, R. M.; NEUTZE, J. M. - Developmental progress following cardiac surgery in infancy using profound hypothermia and circulatory arrest. Circulation, 62: 855-861, 1980.

HOWIE, M. B. - Physiopathology of neurological injury. In: Congresso Brasileiro de Anestesiologia 38, Porto Alegre, 1991. Resumo das contricuiçōes científicas. Porto Alegre, Sociedade de Anestesiologia do Rio Grande do Sul, 1991. p. 13.
7 KASUI, T. S.; INOUE, N.; YAMADA, O.; KOMATSU, S. - Selective cerebral perfusion during operation for aneurysms of the aortic arch: a reassessment. Ann. Thorac. Surg., 53: 109-114, 1992.

8 LEMOLE, G. M.; STRONG, M. D.; SPAGNA, P. M.; KARMILOWICZ, N. P. - Improved results for dissecting aneurysms: intraluminal sutureless prosthesis. J. Thorac. Cardiovasc. Surg., 83: 249-255, 1982.

9 MIDY, D.; LE HUEC, J. C.; DUMONT, D.; CHAUVEAUX, D.; CABANIE, H.; LAUDE, M. - Étude anatomique et histologique des valves des veines jugulaires internes. Bull. Assoc. Anat., 72: 21-29, 1988.

10 MILLS, N. L. \& OCHSNER, J. L. - Massive air embolism during cardiopulmonary bypass: causes, prevention, and management. J. Thorac. Cardiovasc. Surg., 80: $708-717,1980$

11 MOHRI, H.; BARNES, R. W.; WINTERSCHEID, L. C., DILLARD, D. H.; MERENDINO, K. A. - Challenge of prolonged suspended animation: a method of surfaced deep hypothermia. Ann. Surg., 168: 779-787, 1968.

12 MOLINA, J. E.; EINZIG, S.; MASTRI, A. R.; BIANCO, R. W.; MARKS, J. A.; RASMUSSEN, T. M.; CLACK, R. M. - Brain damage in profound hypothermia: perfusion versus circulatory arrest. J. Thorac. Cardiovasc. Surg., 87: 596-604, 1984.

13 MURAOKA, R.; YOKOTA, M.; AOSHIMA, M.; KYOKU, I.; NANOTO, S.; KOBAYASHI, A.; NAKANO, $\mathrm{H}$.; UEDA, K.; SAITO, A.; HOJO, H. - Subclinical 
BRAILE, D. M.; BUFFOLO, E.; ANDRADE, J. C. S.; VOLPE, M. A.; PALMA, J. H.; ZAIANTCHICK, M. - Tratamento cirúrgico das lesōes da aorta torácica utilizando parada circulatória total hipotérmica com perfusāo cerebral retrógrada. Rev. Bras. Cir. Cardiovasc., 7(2):96-106, 1992.

changes in brain morphology following cardiac operations as reflected by computed tomographic scans of the brain. J. Thorac. Cardiovasc. Surg., 81: $364-369,1981$.

14 SAFAR, P. - Therapeutic hypothermia for cardiac arrest. In: Congresso Brasileiro de Anestesiologia, 38, Porto Alegre, 1991. Resumo das contribuiçōes científicas. Porto Alegre, Sociedade de Anestesiologia do Rio Grande do Sul, 1991. p.21.

15 SILVA, J. H. - Proteção cerebral na cirurgia da aorta e seus ramos. In: Congresso Brasileiro de Anestesiologia, 38, Porto Alegre, 1991. Resumo das contribuiçōes científicas. Porto Alegre, Sociedade de Anestesiologia do Rio Grande do Sul, 1991. p.19.

16 TREASURE, T.; NAFTEL, D. C.; CONGER, K. A.; GARCIA, J. H.; KIRKLIN, J. W.; BLACKSTONE, E. $\mathrm{H}$. - The effect of hypotermic circulatory arrest time on cerebral function, morphology, and biochemistry: an experimental study. J. Thorac. Cardiovasc. Surg., 96: 761-770, 1983.

17 UEDA, Y. \& MIKI, S. - Retrograde cerebral perfusion. Ann. Thorac. Surg., 53: 363-368, 1992.

18 UEDA, Y.; MIKI, S.; KUSUHARA, K.; OKITA, Y.; TAHATA, T.; YAMANAKA, K. - Deep hypothermic systemic circulatory arrest and continuous retrograde cerebral perfusion for surgery of aortic arch aneurysm. Eur. J. Cardio-Thorac. Surg., 6: 36-41, 1992.

19 UEDA, Y.; MIKI, S.; KUSUHARA, K.; OKITA, Y.; TAHATA, T.; YAMANAKA, K. - Surgery for aortic arch aneurysm using deep hypothermic circulatory arrest and retrograde cerebral perfusion. J. Jpn. Assoc. Thorac. Surg., 39: 704-706, 1991.

20 UEDA, Y.; MIKI, S.; KUSUHARA, K.; OKITA, Y.; TAHATA, T.; YAMANAKA, K. - Surgical treatment of aneurysm or dissection involving the ascending aorta and aortic arch, utilizing circulatory arrest and retrograde cerebral perfusion. J. Cardiovasc. Surg., 31: 553-558, 1990.

21 USUI, A.; HOTTA, T.; HIROURA, M.; MURASE, M.; MAEDA, M.; KOYAMA, T.; TANAKA, M.; TAKEUCHI, E.; YASUURA, K.; WATANABE, T.; ABE, T. Retrograde cerebral perfusion through a superior vena caval cannula protects the brain. Ann. Thorac. Surg., 53: 47-53, 1992.

\section{Discussāo}

\section{DR. ALTAMIRO RIBEIRO DIAS}

São Paulo, SP

Inicialmente, desejamos agradecer à Comissão Organizadora o honroso convite para comentar este trabalho, e felicitar seus autores pela abordagem deste assunto complexo e árido, que vem passando por ampla revisão. Constitui grande dificuldade clínica e experimental a detecçāo de alteraçōes das funçōes cerebrais superiores, o que, na clínica, exige aplicação seriada de complexa metodologia psicométrica. Vários métodos mais objetivos têm sido utilizados, entre eles tomografias seriadas, estudos radioisotópicos sensíveis, ressonância nuclear magnética repetida etc. $\mathrm{A}$ aplicação destes métodos tem possibilitado o estudo mais acurado de alteraçōes metabólicas cerebrais, alteraçōes de fluxo sangüíneo etc., produzidas por diferentes métodos de proteção, dentre os quais queremos destacar os seguintes: hipotermia profunda (HP), HP intermitente, associada a períodos de reperfusão, $\mathrm{HP}$ + resfriamento tópico, HP + hipofluxo cerebral, perfusão cerebral seletiva via carótidas, cerebroplegia cristalóide de repetição, retroplegia cerebral seletiva, associaçōes. Os autores optaram pela retroperfusāo cerebral e a análise da tabela 3 suscitou-nos dúvidas sobre o emprego do método nos casos 2 e 3 (dissecçōes tipo A). Teria a parada circulatória total sido imposta por más condiçōes da parede aórtica? Outro grande avanço na cirurgia dos aneurismas foi a introdução da cola biológica, a qual vem sendo usada cada vez mais amplamente, simplificando e encurtando o tempo gasto na correção dessas lesōes. A retroperfusão cerebral vem sendo estudada também no InCor-HCFM-USP, tendo sido empregada, até o presente, em 3 pacientes submetidos a tratamento cirúrgico de aneurisma de aorta ascendente, um caso e 2 pacientes com aneurismas da aorta ascendente e arco aórtico, com idades de 43,61 e 54 anos. A técnica utilizada para retroperfusão foi semelhante e os tempos variaram, respectivamente, entre 25,38 e 43 minutos. No terceiro paciente, instalou-se um quadro de confusāo mental e depressão respiratória, que exigiu assistência ventilatória mais prolongada. 0 paciente evoluiu bem, recebendo alta no $31^{2}$ dia de pós-operatório. Achamos que a experiência inicial com o método mostra que ele é bem tolerado e válido como proposta. Entretanto, sua real eficácia quanto à prevenção de alteraçōes das funçōes cerebrais mais complexas demandará, certamente, observaçōes mais acuradas, especialmente com metodologia psicométrica adequada.

\section{DR. BRAILE \\ (Encerrando)}

Agradeço os comentários pertinentes, elucidativos e incentivadores do Prof. Altamiro Ribeiro Dias. Concordamos com o Prof. Altamiro que a avaliaçāo da eficácia do método não é fácil, principalmente porque, do ponto de vista experimental, o procedimento não é reproduzível. Paradas circulatórias de 40 ou mesmo 60 minutos geralmente sāo seguras, 
BRAILE, D. M.; BUFFOLO, E.; ANDRADE, J. C. S.; VOLPE, M. A.; PALMA, J. H.;ZAIANTCHICK, M. - Tratamento cirúrgico das lesōes da aorta torácica utilizando parada circulatória total hipotérmica com perfusão cerebral retrógrada. Rev. Bras. Cir. Cardiovasc., 7(2):96-106, 1992.

porém, acima destes tempos, algum método de proteçāo deve ser implementado. A retroperfusāo é simples e tem evidenciado bons resultados mesmo em tempos longos. Ficamos admirados com o fato de que o sangue que retorna pelas carótidas e demais artérias da cabeça mostra-se bastante insaturado, com temperaturas de $18-20^{\circ} \mathrm{C}$, mostrando que existe um grande consumo de oxigênio $e$, conseqüentemente, de substratos mesmo em hipotermia profunda. O fornecimento de sangue oxigenado por via retrógrada é, portanto, importante, pois este é aproveitado no metabolismo cere- bral. Outro fato importante é que, tanto o ar como outros elementos estranhos săo permanentemente "lavados" por via retrógrada. Quanto aos casos 2 e 3 (dissecções tipo A), esclarecemos que em todos os casos de dissecçăo tipo A fazemos a anastomose distal com parada circulatória total, o que tem melhorado sobremaneira nossos resultados, principalmente pela análise do arco aórtico, onde, muitas vezes, existem descontinuidades da íntima. Concordo que só a experiência clínica a longo prazo dará a validade que esperamos que o método mereça. 